\title{
Morfometria e índices fisiológicos de plântulas de feijão-fava (Phaseolus lunatus L.) em função do tamanho de semente
}

\author{
Rayane Ellen de Oliveira Jerônimo ${ }^{1}$, Juciely Gomes da Silva ${ }^{2}$, Ramon Quaresma Zeferino ${ }^{3}$, Andressa Rodrigues dos \\ Santos $^{4}$, Ariel Roxany da Silva Brasileiro ${ }^{5}$, Rener Luciano de Souza Ferraz ${ }^{6}$
}

\author{
Universidade Estadual da Paraíba, ${ }^{1}$ rayaneoliveira67@live.com, ${ }^{2}$ jucielygomes07@ 0 hotmail.com, \\ ${ }^{3}$ ramomqzeferino@yahoo.com.br, ${ }^{4}$ dessa440@gmail.com, ${ }^{5}$ arielrsb@gmail.com, ${ }^{6}$ ferragroestat@gmail.com.
}

\begin{abstract}
RESUMO: Pertencente à família Fabaceae, a Phaseolus lunatus L., também conhecida como feijão-fava é uma das quatro espécies do gênero Phaseolus explorada comercialmente. A região brasileira onde o cultivo de fava é maior é no Nordeste, sendo a Paraíba o principal estado brasileiro produtor de fava, o maior em área cultivada e de melhor cultivo. A qualidade fisiológica das sementes de fava é pouco estudada, no entanto, informações a esse respeito são importantes, podendo ser utilizadas como subsídios em programas de melhoramento, na conservação da diversidade genética e em estudos filogenéticos. As sementes de fava foram divididas em três tratamentos (pequenas, médias e grandes), cada tratamento possuía sete repetições, com 10 sementes para cada repetição, totalizando 210 sementes. Foram realizadas análises que consistiram na quantificação do comprimento da parte aérea, fitomassa da parte aérea, taxa de crescimento relativo da parte aérea e taxa de acúmulo de fitomassa da parte aérea. Os dados das variáveis de resposta foram submetidos à análise de variância e teste de comparações múltiplas de médias. Verificou-se que o feijão-fava orelha-devó, no que se refere ao CPA, à TCRA e TAFA, não foi influenciado pelo tamanho das sementes. Já a fitomassa da parte aérea foi influenciada significativamente a 5\%, onde as sementes médias e grandes obtiveram maiores resultados. Portanto, as sementes mais indicadas para o plantio de acordo com a fitomassa da parte aérea são as sementes médias e grandes.
\end{abstract}

PALAVRAS-CHAVE: Orelha-de-Vó; Fitomassa; Variedades; Sementes crioulas.

\section{INTRODUÇÃO}

A fava (Phaseolus lunatus L.), pertencente à família Fabacea, é popularmente conhecida como feijão-fava, feijão-de-lima ou fava-de-lima, sendo uma das quatro espécies do gênero Phaseolus mais explorada comercialmente contribui de fomra significativa para o fornecimento de proteínas alimentares (ALVES et al., 2014). Essa família é uma das maiores entre as dicotiledôneas com 643 gêneros e 18.000 espécies distribuídas por todo o mundo, especialmente nas regiões tropicais e subtropicais (BROUGHTON et al., 2003).

No Brasil, possui ampla distribuição, sendo cultivada, principalmente, na região Nordeste, a fava é considerada uma cultura de alto potencial econômico e social (SALES et al., 2017). A Paraíba é o principal estado brasileiro produtor de fava, o maior em área cultivada e de melhor cultivo, com pouca utilização de insumos modernos (NETO et al., 2015).

O seu cultivo é feito tradicionalmente por pequenos agricultores, os quais se utilizam predominantemente de variedades crioulas de crescimento indeterminado (CARMO et al., 2015). A sua importância econômica e social se deve principalmente à sua rusticidade em regiões semiáridas do Nordeste brasileiro, o que possibilita prolongar a colheita em período seco, no entanto a maioria dos produtores enfrenta baixos índices de produtividade (AZEVEDO et al., 2003). Perante o potencial econômico dessa cultura e da falta de informações para sua exploração, tornam-se imprescindíveis os programas de pesquisa em torno da fava (SILVA, 2015).Uma vez que para a agricultura familiar camponesa, um importante desafio na produção agrícola, em que se inclui o feijão-fava, é a conservação dos recursos genéticos, com as sementes que vêm sendo selecionadas e adaptadas aos seus agroecossistemas ao longo dos anos (VASCONCELOS; MATA, 2011)

O estudo morfológico de variedades de feijão-fava é importante porque facilita o registro de caracteres de identificação (OLIVEIRA et al., 2010). Estudos relacionados à qualidade física, fisiológica e morfológica utilizando sementes de feijão-fava são escassos na literatura, no entanto, essas informações são importantes, podendo ser utilizadas como subsídios em programas de melhoramento, na conservação da diversidade genética e em estudos filogenéticos (ADVICÚLA et al., 2015).

Para o desenvolvimento da cultura, o crescimento inicial das plântulas é de suma importância, pois determina a densidade do estande, influencia o grau de infestação das plantas invasoras e a produção por unidade de área (OLIVEIRA, 1990). Esse trabalho teve como objetivo avaliar a morfometria e índices fisiológicos de plântulas de feijão-fava (Phaseolus lunatus L.) em função do tamanho de semente.

\section{MATERIAL E MÉTODOS}

A pesquisa foi realizada na casa de vegetação do Centro de Ciências Agrárias e Ambientais (CCAA) da Universidade Estadual da Paraíba (UEPB) localizada no município de Lagoa Seca $-\mathrm{PB}$, nas coordenadas de Latitude $7^{\circ}$

Caderno Verde de Agroecologia e Desenvolvimento Sustentável (ISSN 2358-2367) v. 9, n.7, e-7036, 2019 doi: $10.18378 /$ cvads.v9i7.7036 
JERONIMO, R. E. O. et al. Morfometria e índices fisiológicos de plântulas de feijão-fava (Phaseolus lunatus L.) em função do tamanho de semente. In: II Congresso Paraibano de Agroecologia \& IV Exposição Tecnológica, 2019. Anais... Caderno Verde de Agroecologia e Desenvolvimento Sustentável, Pombal, v. 9, n.7, e-7036, 2019.

09' S, Longitude $35^{\circ}$ 52' W e altitude de $634 \mathrm{~m}$ (SILVAet al., 2019). Foram utilizadas 210 sementes crioulas do feijãofava do tipo orelha-de-vó, adquiridas de um agricultor familiar do município de Lagoa Seca, PB e transportadas para o CCAA para dar início à pesquisa.

As sementes foram divididas em três tratamentos, sendo tratamento 1 sementes pequenas $(11,22 \mathrm{~mm}$ até 14,03 $\mathrm{mm})$, tratamento 2 sementes médias $(14,04 \mathrm{~mm}$ até $16,85 \mathrm{~mm})$ e tratamento 3 sementes grandes $(16,86 \mathrm{~mm}$ até 19,66 $\mathrm{mm}$ ), cada tratamento possuía 7 repetições, com 10 sementes em cada repetição, totalizando 210 sementes. Plantadas em 3 bandejas de polietileno com dimensões de $30,3 \mathrm{~cm}$ x 22,1 $\mathrm{cm}$ x 7,5 cm de comprimento, largura e altura, respectivamente, preenchidas com $3,0 \mathrm{~kg}$ de substrato arenoso..

Foram realizadas análises que consistiram na quantificação do comprimento da parte aérea (CPA), fitomassa da parte aérea (FMA), taxa de crescimento relativo da parte aérea (TCRA) e taxa de acúmulo de fitomassa da parte aérea (TAFA) (FERRAZ et al., 2017).

No período de 6 dias foram retiradas duas plantas uniformes por repetição, nas quais foram realizadas medições para determinação do comprimento médio inicial da parte aérea (CIA), os quais foram aferidos utilizando-se de régua graduada em cm (Figura 1). Posteriormente, as duas plantas foram seccionadas separando a raiz da parte aérea. $\mathrm{O}$ material vegetal foi acondicionado em sacos de papel e conduzido à estufa de circulação de ar forçada a $70{ }^{\circ} \mathrm{C}$ até atingirem massa constante, para posterior pesagem em balança analítica e determinação da fitomassa inicial da parte aérea (FIA) (FERRAZ et al., 2017). Transcorridos 12 dias de implantação do experimento, dentre as plantas restantes, foram selecionadas duas por repetições, nas quais foram realizadas medições para determinação do comprimento médio da parte aérea (CFA) o material vegetal foi seccionado, acondicionado e seco para determinação da fitomassa da parte aérea (FFA).

Figura 1. Avaliações do crescimento da parte aérea da planta.

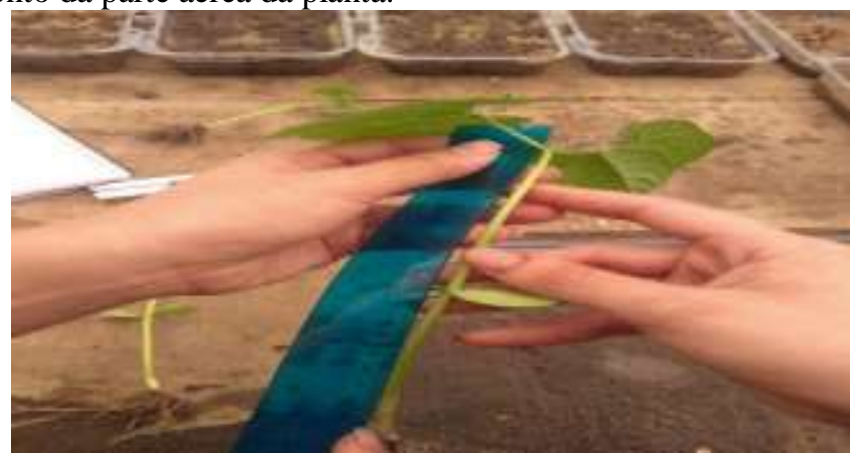

Com base nos dados obtidos na etapa anterior, foi realizada a determinação da taxa de crescimento relativo da parte aérea (TCRA) e taxa de acúmulo de fitomassa da parte aérea (TAFA), sendo essa variável obtida por meio da relação: $R=\frac{\ln W 2-\ln W 1}{t 2-t 1}$, em que: $R=$ taxa de crescimento ou ganho relativo; $\ln =\operatorname{logarítmoneperiano;~} \mathrm{W}_{1}=$ comprimento ou fitomassa inicial; $\mathrm{W}_{2}=$ comprimento ou fitomassa; $\mathrm{t}_{1}=$ tempo inicial e $\mathrm{t}_{2}=$ tempo (ECHER et al., 2010). Os dados das variáveis de resposta foram submetidos à análise de variância e teste de comparações múltiplas de médias através do Software para análises estatísticas - Sisvar (FERREIRA, 2014).

\section{RESULTADOS E DISCUSSÃO}

Verificou-se que o feijão-fava orelha-de-vó, no que se refere ao comprimento da parte aérea (CPA), não foi influenciado significativamente pelo tamanho da semente (pequenas, médias e grandes). Já a fitomassa da parte aérea foi influenciada significativamente pelo tamanho das sementes a 5\%. Em relação à taxa de crescimento relativo da parte aérea (TCRA) e a taxa de aumento de fitomassa na parte aérea (TAFA) não foi constatada diferença significativa (Tabela 1).

Tabela 1. Resumo das análises de variância para comprimento da parte aérea, fitomassa da parte aérea, taxa de crescimento relativo da parte aérea e taxa de acúmulo de fitomassa na parte aérea. Lagoa Seca, PB, 2019.

\begin{tabular}{lccccc}
\hline \multirow{2}{*}{ FV } & \multirow{2}{*}{ GL } & \multicolumn{4}{c}{ Quadrados médios } \\
\cline { 2 - 6 } & 2 & CPA & FMA & TCRA & TAFA \\
\hline Comprimento & $25,91^{\text {ns }}$ & $0,11^{*}$ & $4,5 \mathrm{e}-5^{\text {ns }}$ & $1,0 \mathrm{e}-4^{\text {ns }}$ \\
Erro & 18 & $18,00^{\text {ns }}$ & $0,02^{*}$ & $2,5 \mathrm{e}-4^{\text {ns }}$ & $1,8 \mathrm{e}-4^{\text {ns }}$ \\
CV $(\%)$ & & 11,91 & 15,79 & 26,43 & 29,29 \\
\hline
\end{tabular}

Os resultados das médias do comprimento da parte aérea deram não significativos, ou seja, as sementes pequenas $(33,18 \mathrm{~cm})$, médias $(38,29 \mathrm{~cm})$ e grandes $(35,4 \mathrm{~cm})$ não se diferem em relação ao crescimento aéreo (Figura $2 \mathrm{~A})$. Em 
JERONIMO, R. E. O. et al. Morfometria e índices fisiológicos de plântulas de feijão-fava (Phaseolus lunatus L.) em função do tamanho de semente. In: II Congresso Paraibano de Agroecologia \& IV Exposição Tecnológica, 2019. Anais... Caderno Verde de Agroecologia e Desenvolvimento Sustentável, Pombal, v. 9, n.7, e-7036, 2019.

relação à fitomassa da parte aérea, as sementes pequenas obtiveram $(0,76 \mathrm{mg})$, as médias $(0,96 \mathrm{mg})$ e as grandes $(1,01 \mathrm{mg})$, sendo o resultado significativo a $5 \%$ (Figura 2B). Resultado esse que agiliza o trabalho do agricultor familiar no campo, onde o mesmo não terá que selecionar as sementes entre pequenas, médias e grandes na hora do plantio. Entretanto, esse resultado pode ter sido influenciado pelo uso de bandejas de polietilenos onde a profundidade é de $7,5 \mathrm{~cm}$, o que pode ter impedido o crescimento e desenvolvimentos das plantas, obtendo esse resultado. Recomenda-se que nos estudos futuros, utilizem recipientes com uma profundidade maior que $10 \mathrm{~cm}$. Uma pesquisa realizada por Advicúla et al. (2015) evidenciou que a variedade de fava orelha-de-vó obteve maior acúmulo de massa seca da parte aérea, os valores oscilaram entre 2,84 a 5,86 g, comparada a outras variedades analisadas.

Em um estudo realizado por Melo et al. (2009), estes pesquisadores observaram que a cultura da fava apresentou um crescimento em fitomassa aérea sempre crescente, mesmo na fase de colheita, sugerindo continuidade de crescimento durante essa fase de desenvolvimento da planta. Comportamento comum em culturas que possuem hábito indeterminado de crescimento, como a maioria das variedades de fava exploradas no Brasil.

Figura 2. Comprimento da parte aérea (A). Fitomassa da parte aérea (B) de plântulas de fava orelha-de-vó em função dos tamanhos das semente. Lagoa Seca/PB, 2019.

A

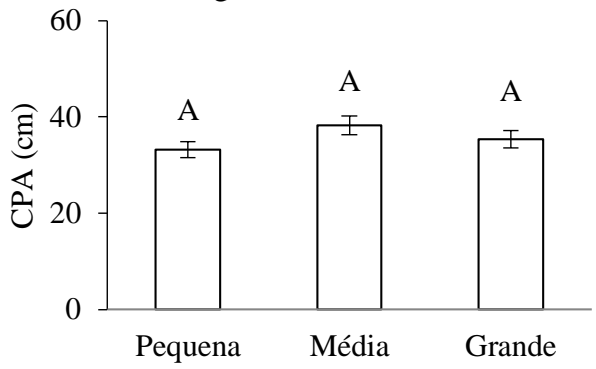

B

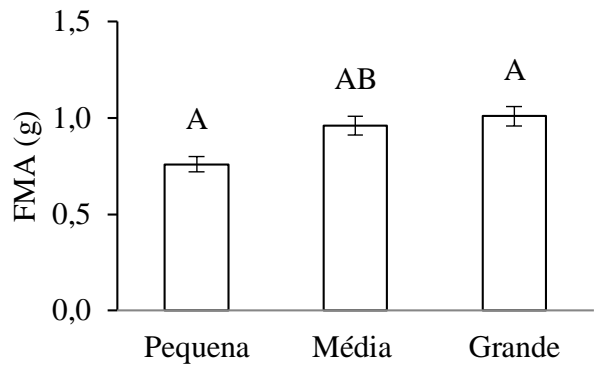

Minuzziet al. (2010) afirmam que qualidade fisiológica das sementes é de grande importância na avaliação de um lote de sementes porque tem influência direta em seu desempenho. As médias da taxa de crescimento relativo das plântulas oriundas de sementes pequenas $(0,05 \mathrm{~cm})$, médias $(0,06 \mathrm{~cm})$ e grandes $(0,05 \mathrm{~cm})$ (Figura 3A) não tiveram diferenças significativas. A taxa de acúmulo de fitomassa das s plântulas geradas a partir de sementes pequenas $(0,04 \mathrm{~g})$, médias $(0,04 \mathrm{~g})$ e grandes $(0,04 \mathrm{~g})$ (Figura 3B) não teve diferença significativa. Quanto ao conteúdo de massa seca de parte aérea Silva (2017) observou em um estudo com variedades da família Fabacea que o maior valor ocorreu na cultivar feijão-macassar (28,32 g), não diferindo estatisticamente dos cultivares de feijão-fava Olho de Cabra e Orelha de Vó.

Figura 3. Taxa de crescimento relativo da parte aérea (A). Taxa de acúmulo da fitomassa na parte aérea (B) de plântulas de fava orelha-de-vó em função dos tamanhos das semente. Lagoa Seca/PB, 2019.
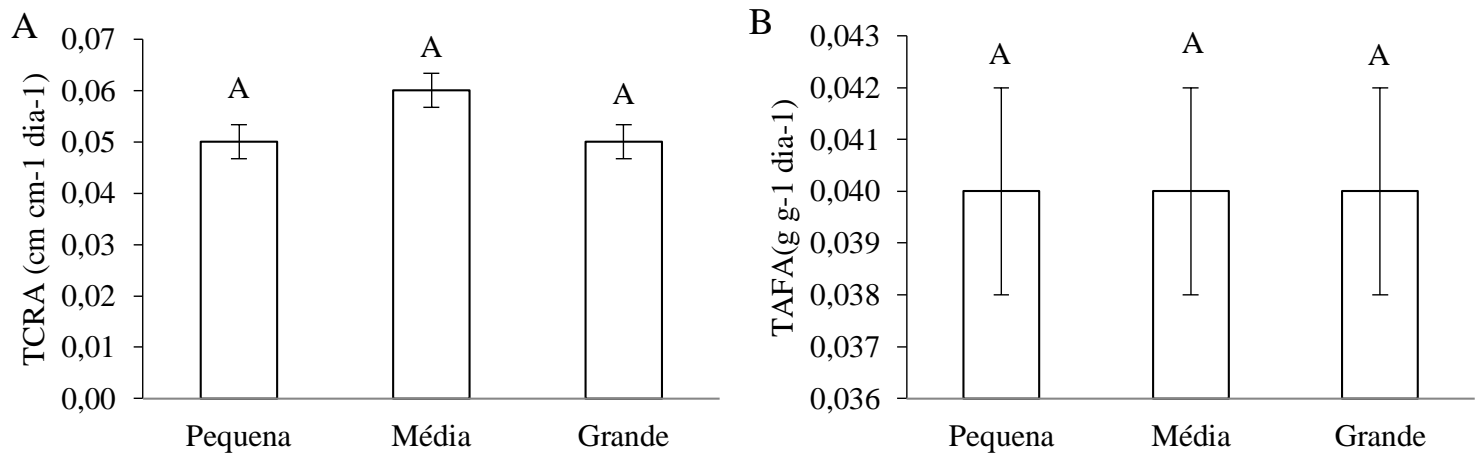

Em uma pesquisa realizada por Silva e Dultra Filho (2018) no município de Pombal-PB, não foram observados efeitos significativos em relação aos parâmetros agronômicos observados, comprimento da planta (CP), diâmetro do caule (DC), matéria fresca (MFPA) e matéria seca (MSPA) dos acessos de feijão fava. Os autores afirmam a necessidade de novos estudos com as cultivares analisadas para uma melhor qualidade fisiológica da semente. Pois sementes de melhor qualidade fisiológica são menos sensíveis às condições de campo, como estresse hídrico após a semeadura, e menos suscetíveis ao ataque de pragas, além de proporcionar uniformidade e rápido desenvolvimento do estande, dificultando o aparecimento de plantas invasoras (MELO et al., 2016).

\section{CONCLUSÕES}

O tamanho das sementes não influencia de forma significativa a morfometria e índices fisiológicos de plântulas de fava orelha-de-vó, embora sementes médias e grandes promovam maior acúmulo de fitomassa da parte aérea, de modo que sementes médias são as mais indicadas para o plantio. 
JERONIMO, R. E. O. et al. Morfometria e índices fisiológicos de plântulas de feijão-fava (Phaseolus lunatus L.) em função do tamanho de semente. In: II Congresso Paraibano de Agroecologia \& IV Exposição Tecnológica, 2019. Anais... Caderno Verde de Agroecologia e Desenvolvimento Sustentável, Pombal, v. 9, n.7, e-7036, 2019.

\section{REFERÊNCIAS}

ADVÍnCUlA,T. L.; NADAI, F. B.; NOBRE, D. A. C.; FERREIRA, E. N. M. B.; BRANDÂO JÚNIOR, D, S.; COSTA, C. A. Qualidade física e fisiológica de sementes de Phaseolus lunatus L. Revista Brasileira de Ciências Agrárias. Recife, v.10, n.3, p.341-346, 2015.

ALVES, A. U.; CARDOSO, E. A.; ALIXANDRE, T. F.; CAVALCANTE, I. H. L.; BECKMANN-CAVALCANTE,M. Z. Emergência de plântulas de fava em função de posições e profundidades de semeadura. Biosciencies Journal, v. 30 , n.1, p. 33-42,2014.

AZEVEDO, J. N.; FRANCO, L .J. D. ARAÚJO, R. O. C. Composição química de sete variedades de feijão-fava. Teresina: Embrapa Meio Norte, 2003.

BROUGHTON, W. J.; HERNANDEZ, G.; BLAIR, M.; BEEBE, S. GEPTS, P.; VANDERLEYDEN, J.. Beans (Phaseolus spp.) - model food legumes. Plant and soil, v.252, n.1, p.55-128, 2003.

CARMO, M. D. S.; CARVAlhO, E. M. S.; GOMES, R. L. S.; LOPES, A. C. A.; CAVAlCANTE, G, R. S. et al. Avaliação de acessos de feijão-fava, para resistência a Colletotrichumtruncatum, em condições de folhas destacadas e campo.Summa Phytopathol, v. 41, n. 4, p. 292-297, 2015.

ECHER, F. R.; CUSTODIO, C. C.; HOSOMI, S. T.; DOMINATO, J. C.; MACHADO-NETO, N. B. Estresse hídrico induzido por manitol em cultivares de algodão.Revista Ciência Agronômica, Fortaleza, v. 41, n. 4, p. 638-645, 2010.

FERRAZ, R. L. S.; BARBOSA, M. A.; MAGALHÃES, I. D.; MELO, A. S.; ROCHA, M. S.; COSTA, P. S.. Atributos qualitativos de sementes de algodoeiro hidrocondicionadas em soluções de silício. Científica, São Paulo, v. 45, n. 1, p. 85-94, 2017.

FERREIRA, D. F. Sisvar: a Guide for its Bootstrap procedures in multiplecomparisons. Ciência e Agrotecnologia, v.38, n.2, p.109-112, 2014.

MELO, L. J. V.; FERNANDES, P. D.; GHEYI, H. H.; BARREIRO-NETO, M.; FRANCO, C. F. O. Crescimento e produção de fava em função de lâminas de irrigação e densidade de plantio. Tecnologia \& Ciência Agropecuária, v.3, n.2, p.37-41, 2009.

MELO, D.; BRANDÃO, W. T. M.; NOBREGA, L. H. P.; WERNCKE, I. Qualidade de sementes de soja convencional e RoundupReady (RR), produzida para consumo próprio e comercial. Revista de Ciências Agrárias, v. 39, n. 2, p. 300-309, 2016.

MINUZZI, A.; BRACINNI, A. L.; RANGEL, M. A. S.; SCAPIM, C. A.; BARBOSA, M. C.; ALBRECHT, L. P. Qualidade de sementes de quatro cultivares de soja, colhidas em dois locais no estado de Mato Grosso do Sul. Revista Brasileira de Sementes, v. 32, n. 1, p. 176-185, 2010.

NETO, M. B.; FAgUndes, R. A. A.; BARbOSA, M. M.; ARRIEL, N. H. C.; FRANCO, C. F. O.; SANTOS, J. F. Características morfológicas e produtivas em acessos de feijão-fava consorciados. Tecnologia \& Ciência Agropecuária,v.9, n.3. p 23-27, 2015.

OLIVEIRA, M.A. Investigações preliminares sobre a emergência e o crescimento inicial de diferentes cultivares de grão-de-bico (Cicerarietinum L.) sob três níveis iniciais de unidade no substrato. Monografia de graduação. UNESP, Jaboticabal, 1990

OLIVEIRA, F. N.; TORRES, B. S.; BEBEDITO, C. P. Caracterização botânica e agronômica de acessos de feijão-fava, em Mossoró, RN. Revista Caatinga, vol. 24, núm. 1, p. 143-148, 2011.

SALES, J. R. S.; SALES, J. R. S.; MAGALHÃES, C. L.; SARAIVA, S. E. L.; LEITE, K. N.. Crescimento inicial de plantas de fava irrigada com águas salinas em solos com biofertilizantes. In: IV INOVAGRI Internacional Meeting, 2017, Fortaleza. Anais... Fortaleza. III Simpósio Brasileiro de Salinidade, 2017.

SHAPIRO, S. S.; WILK, M. B.An Analysis of Variance Test for Normality (Complete Samples).Biometrika Trust, v. 52, p. 591-609, 1965. 
JERONIMO, R. E. O. et al. Morfometria e índices fisiológicos de plântulas de feijão-fava (Phaseolus lunatus L.) em função do tamanho de semente. In: II Congresso Paraibano de Agroecologia \& IV Exposição Tecnológica, 2019. Anais... Caderno Verde de Agroecologia e Desenvolvimento Sustentável, Pombal, v. 9, n.7, e-7036, 2019.

SILVA, A. E.; FERRA, R. L. S.; COSTA, P. S.;VIEGAS, P. R. A.; MELO, A. S.; MEIRA, K. S.; SOARES. C. S.; MAGALHÃES, I. S.; MEDEIROS, A. S. Microclimate changes, photomorphogenesis, and water consumption by Moringa oleifera cuttings under light spectrum variations and exogenous phytohormones concentrations. Australian Journal Of Crop Science, 2019.

Silva, A. G. da.; CAVAlCANTE, A. C. P.; OlIVEIRA, D. S.; SILVA, M. J. R.. Crescimento inicial de Phaseolus lunatus L. submetido a diferentes substratos orgânicos eaplicação foliar de urina de vaca. ACSA - Agropecuária Científica no Semiárido. V. 11, n. 1, p. 131-135, 2015.

SILVA, R. T. Qualidade fisiológica de sementes crioulas de Fabaceae. 2017. 45 fls. Monografia (Graduação em Agronomia)- Universidade Federal da Paraíba, Areia, 2017.

SILVA, W. I.; DULTRA FILHO, J. A. Avaliação de caracteres agronômicos e genéticos em acessos de feijão fava no município de Pombal, no semiárido paraibano. XV congresso de iniciação científica da Universidade Federal de Campina Grande. Anais... Campina Grande: XV CICUFCG, 2018.

VASCONCELOS, J.M.G.; MATA, M.F. Casas de sementes comunitárias: estratégias de sustentabilidade alimentar e preservação da biodiversidade no semi-árido cearense. Cadernos de Agroecologia, v.6, p.1-5, 2011.

\section{AGRADECIMENTOS}

Apoio financeiro: Fundação de Apoio à Pesquisa do Estado da Paraíba - FAPESQ. 